\title{
Electrophysiological and pharmacological evaluation of the nicotinic cholinergic system in chagasic rats
}

Rafael Bonfante-Cabarcas ${ }^{1,3^{*}}$, Erlymar López Hincapié ${ }^{1,3}$, Eliezer Jiménez Hernández ${ }^{1,3}$, Ruth Fonseca Zambrano ${ }^{1,3}$, Lady Ferrer Mancini ${ }^{1,3}$, Marcos Durand Mena ${ }^{1,3}$ and Claudina Rodríguez-Bonfante ${ }^{2,3}$

\begin{abstract}
Background: Two theories attempt to explain the changes observed in the nicotinic acetylcholine receptors (nAChRs) in chagasic cardiomyopathy. The neurogenic theory proposes that receptor changes are due to loss of intracardiac ganglia parasympathetic neurons. The immunogenic theory proposes that the nAChRs changes are the result of autoantibodies against these receptors. Both theories agreed that nAChRs functional expression could be impaired in Chagas disease.
\end{abstract}

Methods: We evaluated nAChRs functional integrity in 54 Sprague Dawley rats, divided in two groups: healthy and chronic chagasic rats. Rats were subjected to electrocardiographic studies in the whole animal under pentobarbital anesthesia, by isolation and stimulation of vagus nerves and in isolated beating hearts (Langendorff's preparation).

Results: Nicotine, $10 \mu \mathrm{M}$, induced a significant bradycardia in both groups. However, rats that had previously received reserpine did not respond to nicotine stimulation. $\beta$-adrenergic stimulation, followed by nicotine treatment, induced tachycardia in chagasic rats; while inducing bradycardia in healthy rats. Bilateral vagus nerve stimulation induced a significantly higher level of bradycardia in healthy rats, compared to chagasic rats; physostigmine potentiated the bradycardic response to vagal stimulation in both experimental groups. Electric stimulation (e.g., $\geq 2 \mathrm{~Hz}$ ), in the presence of physostigmine, produced a comparable vagal response in both groups. In isolated beating-heart preparations $1 \mu \mathrm{M}$ nicotine induced sustained bradycardia in healthy hearts while inducing tachycardia in chagasic hearts. Higher nicotine doses (e.g.,10 - $100 \mathrm{uM}$ ) promoted the characteristic biphasic response (i.e., bradycardia followed by tachycardia) in both groups. $10 \mathrm{nM}$ DHßE antagonized the effect of $10 \mu \mathrm{M}$ nicotine, unmasking the cholinergic bradycardic effect in healthy rats only. $1 \mathrm{nM}$ a-BGT alone induced bradycardia in healthy hearts but antagonized the $10 \mu \mathrm{M}$ nicotine-induced tachycardia in chagasic rats. In healthy but not in chagasic hearts, $10 \mu \mathrm{M}$ nicotine shortened PQ and PR interval, an effect counteracted by MA, DHBE and aBGT

Conclusion: Our results suggest that cholinergic function is impaired in chronic Chagas disease in rats, a phenomena that could be related to alteration on the nAChR expression.

Keywords: Vagal stimulation, Isolated beating hearts, Nicotine, Chagas disease, Mecamylamine, DHßE, a-BGT

\footnotetext{
* Correspondence: rcabarca@ucla.edu.ve

${ }^{1}$ Biochemistry Research Units, Health Sciences School, Universidad Centro

Occidental Lisandro Alvarado, Barquisimeto, Lara, Venezuela

${ }^{3}$ Libertador Av. con Andrés Bello, Unidad de Bioquímica, Decanato de

Ciencias de la Salud, Universidad Centro-Occidental "Lisandro Alvarado",

Barquisimeto, Estado Lara Código Postal: 3001, Venezuela

Full list of author information is available at the end of the article
} 


\section{Background}

Chagas disease, caused by Trypanosome cruzi (T cruzi), is considered a serious public health problem in Central and South America countries [1]. In Venezuela, approximately 4 million people are at risk to develop Chagas disease [2]. The chagasic chronic cardiomyopathy (CCC) is the most common complication of this disease; approximately 25$30 \%$ of infected patients developed CCC [1].

Although the CCC pathogenesis is not completely understood, two theories attempt to explain it: the neurogenic theory postulates that $\mathrm{CCC}$ is the result of myocardial denervation. During the acute phase of the disease, $T$ cruzi's invasion of the myocardium results in a selective, mechanical destruction of the intracardiac postganglionic parasympathetic neurons. The destruction of the parasympathetic neurons allows for a sustained noncounteracted sympathetic tone; this unbalanced sympathetic stimulation initiates trophic changes that result in the myocardial remodeling that culminates in arrhythmias and heart failure [3].

The immunogenic theory explains the CCC pathogenesis as the result of an aberrant immune response that includes loss of self-tolerance and the development of cross-reacting antibodies. Due to molecular mimicry, cross-reacting antibodies bind and neutralize surface receptors such as nAChRs. These cross-reacting antibodies (i.e., autoantibodies) affect the activity and number of those receptors population [4-7].

Nicotinic acetylcholine receptors (nAChRs) are pentameric, ligand-gated ion channels, formed by $\alpha$ and $\beta$ subunits. Eight $\alpha$ subunits $\left(\alpha_{2}-\alpha_{7}, \alpha_{9}, \alpha_{10}\right)$ and three $\beta$ subunits $\left(\beta_{2}-\beta_{4}\right)$ have been described; the combination of these subunits produces a wide variety of functional receptors [8]. Intracardiac ganglion neurons can express $\alpha_{2}$ to $\alpha_{9}$ and $\beta_{2}$ to $\beta_{4}$ subunits, assembled predominantly as $\alpha_{3} / \beta_{2}, \alpha_{3} / \beta_{4}$, $\alpha_{3} / \beta_{2} / \beta_{4}, \alpha_{3} / \beta_{2} / \alpha_{5}, \alpha_{3} / \beta_{4} / \alpha_{5}$, and monomeric $\alpha_{7}$. For example, the canine intracardiac ganglion expresses predominately $\alpha_{3} / \beta_{2}$ nAChRs, with a smaller levels of $\alpha 7$ nAChRs [9-12].

Both neurogenic and immunogenic theories propose alterations in the function of the cholinergic system. Recently, our group demonstrated the existence of trophic and functional disturbances of the muscarinic cholinergic receptor system on in vivo and in vitro rats' models of Chagas disease $[13,14]$. In the present study, we analyzed the functionality of the nAChRs in the whole animal and in isolated beating-heart preparations, of healthy and chagasic Sprague Dawley rats.

\section{Methods}

All drugs and chemicals were purchased from SigmaAldrich Co (St. Louis, MO, USA) and prepared as $\mathrm{mg} / \mathrm{ml}$ or $\mathrm{M}$ stocks solution by dissolving the drugs in purified deionized water. Stocks solutions were alliquoted and stored at $5^{\circ} \mathrm{C}$ until use.

\section{Animal model}

All experiments were carried out on 54 Sprague Dawley rats, randomly distributed according to the experiment: 16 (8 healthy and 8 chagasic rats) for the whole animal experiments, 15 (8 healthy and 7 chagasic) were treated with reserpine, and 23 (11 healthy and 12 chagasic) were used in vagal stimulation and isolated beating heart experiments. The MHOM/VE/92/2-92-YBM trypomastigotes strain was used to induce infection. Experimental animal (i.e., rats) were inoculated with 1.000 trypomastigotes per gram of body weight (chagasic group). Chagasic animals develop an acute disease with a parasitemia peak of $67.27 \pm 25.05 \times 10^{6}$ parasites $/ \mathrm{ml}$ at the third week of infection. At the time of performing the experiments, the animals had $7.84 \pm 0.45$ months-old, weighted $504.9 \pm$ 10.74 and $418.5 \pm 15.10$ grs for healthy and chagasic rats, respectively; and only two chagasic animals displayed parasites in a blood sample, giving a parasitemia of $114.9 \pm$ 84.43 parasites $/ \mathrm{ml}$. Animals were individually housed in a temperature-controlled environment with a 12:12 light/ dark cycle and free access to food and water. Experimental protocols were approved by the ethical committee of the School of Health Sciences following the American Physiological Society guidelines.

\section{Vagus nerve stimulation (VNS)}

The animals were anesthetized using a pentobarbital (20-40 mg/Kg) and ketamine (50 mg/Kg) cocktail administered intraperitoneally. The animals' respiration was mechanically aided through a tracheal cannula connected to a volume-controlled rodent respirator at a frequency of 70 strokes/min to facilitate ventilation in spontaneously breathing rat. The cervical vagus nerve was exposed bilaterally and severed at the caudal terminus. Platinum bipolar electrodes were attached to the nerves ending leading toward the heart. The electrodes were connected to a PowerLab/8sp system to generate frequency of heart pacing . During the experiments performance, the electric pulses were modified according to the protocol. Impulses were delivered either at a fixed frequency $(1.5 \mathrm{~Hz})$ but different potency ranges $(0.25$ to $3 \mathrm{~V})$ or in a range of frequencies (1-4 Hz) but fixed potency $(2 \mathrm{~V})$. All experiments were performed in the absence and presence of $0.3 \mathrm{mg} / \mathrm{Kg}$ physostigmine.

\section{Isolated beating-heart system}

The animals were anesthetized as described above and the hearts removed under aseptic conditions. The isolated 
hearts were connected to a Langendorff's perfusion system by cannulation of the aorta. The hearts were perfused with a tepid $\left(37^{\circ} \mathrm{C}\right)$ modified physiological solution $(\mathrm{pH} 7.40$ \pm 0.05 ), aerated with a $95 \% \mathrm{O}_{2}$ and $5 \% \mathrm{CO}_{2}$ mixture. Perfusion was conducted at a rate of $7-10 \mathrm{~mL} / \mathrm{min}$ maintaining a pressure range of 50 to $100 \mathrm{mmHg}$. The perfusion solution composition included $10 \mathrm{mM}$ glucose, $1 \mathrm{mM}$ $\mathrm{MgSO}_{4}, 116 \mathrm{mM} \mathrm{NaCl}, 18 \mathrm{mM} \mathrm{NaHCO}, 2.5 \mathrm{mM} \mathrm{CaCl}_{2}$, $5 \mathrm{mM} \mathrm{KCl}$, and $1 \mathrm{mM}$ malate.

To evaluate the effect of nicotine stimulation on the chagasic and control hearts' rate, the isolated hearts were perfused, for 5 minutes, with 1,10 or $100 \mu \mathrm{M}$ of nicotine. The heart preparations were allowed a $10 \mathrm{~min}$ rest period between doses - maintaining perfusion with modified physiological solution. The effect of the following nAChRs' antagonists, on the isolated hearts' rate, was evaluated: $1 \mu \mathrm{M}$ mecamylamine (MA, $\alpha_{3} / \beta_{4} \mathrm{nAChR}$ antagonist), $10 \mathrm{nM}$ dihydro- $\beta$-erythroidine (DH $\beta E ; \alpha_{4} / \beta_{2} \mathrm{nAChR}$ antagonist), and $1 \mathrm{nM} \alpha$-bungarotoxin ( $\alpha$-BGT; $\alpha_{7} \mathrm{nAChR}$ antagonist) [15]. The antagonists were administered in the perfusion solution for 10 minutes, in the absence of nicotine, and for additionally 5 minutes in the presence of $10 \mu \mathrm{M}$ nicotine. The preparations were allowed a $10 \mathrm{~min}-$ utes resting period - perfusion with modified physiological solution - between antagonists administration.

\section{EKG recording}

In the VNS experiments, the hearts' electric activity was monitored using needle electrodes placed subcutaneously on the sternum xiphoid process and on both shoulders the left shoulder electrode served as reference electrode. In the isolated heart preparations, the positive electrode was inserted into the heart's apex and the negative electrode into the right atrium. Analogical EKG signals were amplified using BioAmp, transformed in digital signals by Power Lab 8 data acquisition unit, recorded and analyzed using Lab Chart software (ADInstruments).

\section{Data analysis}

Data are expressed either as mean of absolute values \pm SEM or normalized to be expresed as percentages \pm SEM. Paired and non-paired Student's t-test were used to analyze the effect of a drug on a particular group in matched observations or when a variable for the control group was compared with the same variable of the Truzi infected group, respectively. Repeated measure analysis of variance (rANOVA) followed by a Dunnet's post-test were peformed to determine the statistical significance of drug concentration and time effect per group. In all analyses, a $p$ value $<0.05$ was considered statistically significant. Statistical analysis were performed using the GraphPad Prism 4 for Windows software (GraphPad Software Inc, La Jolla, CA).

\section{Results}

\section{EKG study in intact animals}

The significant bradycardia induced by $10 \mu \mathrm{M}$ nicotine, in healthy and chagasic rats, was reverted by $0.1 \mu \mathrm{M}$ d-tubocurarine (Figures $1 \mathrm{~A}$ and $1 \mathrm{C}$ ). Lower concentrations of nicotine appear to have no effect on the heart rate of the animals.

In order to determine whether the catecholaminergic neurons were involved in the bradycardic response, the synaptic amine content was depleted with reserpine $(1 \mathrm{mg} / \mathrm{Kg} /$ day for three days) in both control and chagasic animals. It was observed that reserpine-treated animals (both groups) had a lower basal heart rate and nicotine was unable to induce bradycardia (Figure 1B and 1D).

When adrenergic tone was enhanced $(0.01 \mathrm{mg} / \mathrm{Kg}$ of isoproterenol), a similar tachycardic response $(\mathrm{p}=0.14)$ was induced in both animals groups (i.e., $117.2 \% \pm 1.54$ in the healthy group and $120.6 \% \pm 1.68$ in the chagasic rats). After administration of $10 \mathrm{uM}$ of nicotine, we observed that nicotine induced bradycardia in the healthy group while, surprisingly, inducing a significant tachycardia in the chagasic animals (Figure 2).

\section{NVS study in intact animals}

Stimulation of both vagus nerves induced a proportional bradycardia to the frequency of the stimulus. However, the bradycardic response was significantly higher in healthy rats, compared with chagasic rats (Figure 3A). Physostigmine potentiated the bradycardic response, in both experimental groups; at low frequencies (1 and $1.5 \mathrm{~Hz}$ ) the bradycardic response was significantly higher in healthy rats but, a higher frequencies ( 2 to $4 \mathrm{~Hz}$ ) bradycardia was similar in both groups (Figure 3B).

Likewise, at low frequency stimulation $(1.5 \mathrm{~Hz})$, a significant bradycardic response was elicited as the voltage intensity increased above $0.5 \mathrm{~V}$. A significant difference between the groups was observed at $3 \mathrm{~V}$ when the vagus nerves' data were analyzed together (Figure 3C). Physostigmine potentiated the bradycardic response, with the resulting response significantly higher, at 2 and $2.5 \mathrm{~V}$, for healthy rats compared with chagasic rats (Figure 3D).

\section{Isolated beating-hearts study \\ Heart rate}

Figure 4 illustrates the effect of nicotine on the heart rate of healthy and chagasic hearts. Nicotine $(1 \mu \mathrm{M})$ slow-down the heart rate for $150 \mathrm{sec}$ in healthy hearts $(-4.9 \pm 2.1 \%$; $\mathrm{p}<0.05)$, while in the chagasic hearts induced a transient but non-significant, decrease on the hearts rate (20 s), followed by a significant tachycardia $(+2.6 \pm 1 \%, \mathrm{p}<0.05)$ (see Figure 4A). The response of healthy and chagasic hearts to $10 \mu \mathrm{M}$ nicotine stimulation (Figure 4B) was comparable to that induced by $1 \mu \mathrm{M}$ nicotine in the chagasic hearts. Initially, $10 \mu \mathrm{M}$ nicotine induced a non-significant bradycardia 
A
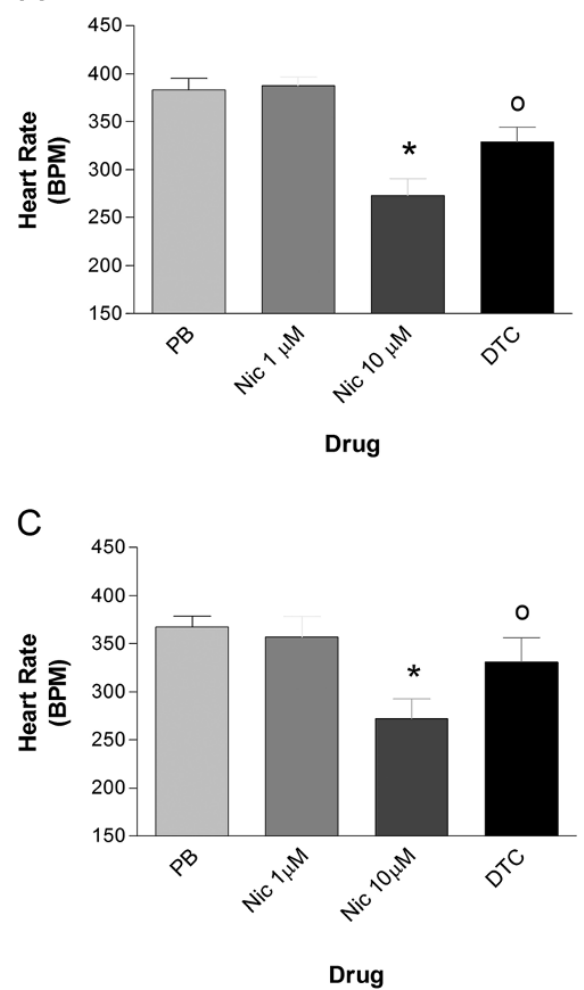

B

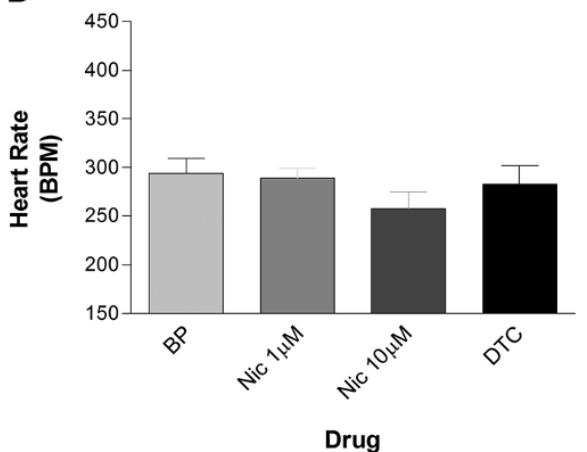

D

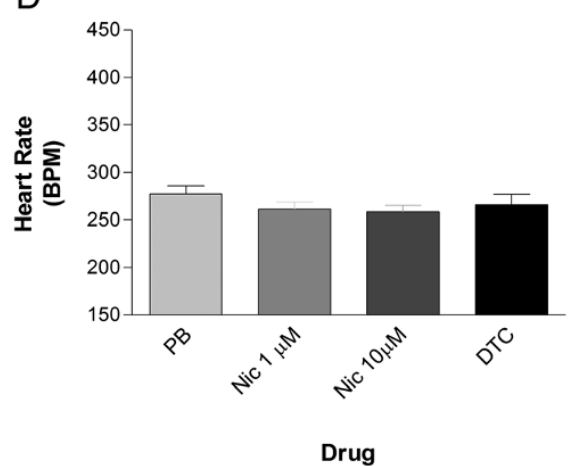

Figure 1 Nicotine affects the heart rate of anesthetized whole-animals. $10 \mu \mathrm{M}$ Nicotine (Nic) induced a significant bradycardic response, while $1 \mu \mathrm{M}$ D-tubocurarine reversed it, in both healthy $(\mathbf{A})$ and chagasic $(\mathbf{C})$ rats. Lower doses of Nic (i.e., $1 \mu \mathrm{M})$ have no effect on the heart rate of these animals. EKG results from healthy (B) and chagasic (D) rats, treated daily with $1 \mathrm{mg} / \mathrm{Kg}$ of reserpine for 3 days, showed a significant decrease of heart rate compared to untreated animals; however, $10 \mu \mathrm{M}$ of nicotine has no bradycardic effect on reserpine-treated healthy (B) or chagasic (C) animals.

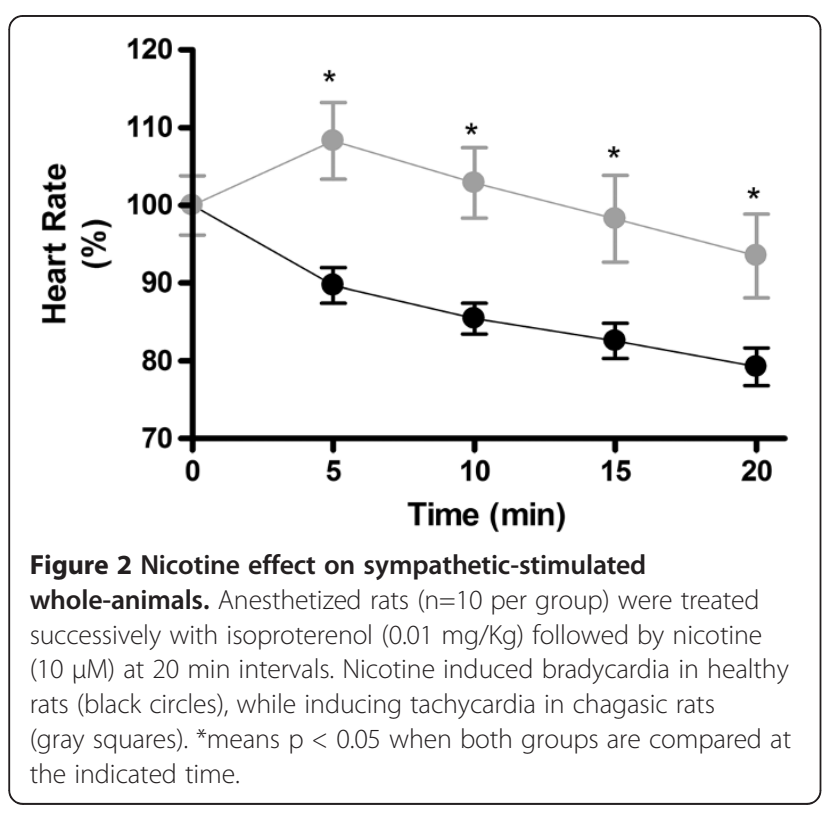

$(-2 \pm 1.5 \%, \mathrm{p}>0.05)$ that was followed by a significant tachycardia $(+5.8 \pm 3.5 \%$ in healthy group; $+4 \pm 1.9 \%$ in chagasic group. $\mathrm{p}<0.05)$. The effect of $100 \mu \mathrm{M}$ nicotine was similar to that induced by $10 \mu \mathrm{M}$ nicotine in both groups.

In the absence of nicotine stimulation, healthy hearts response to MA was a slight but significant $(\mathrm{p}<0.05)$ bradycardia (2.24 to $2.92 \%)$. Chagasic hearts response to MA was non-significant. However, $1 \mu \mathrm{M}$ MA abrogated the tachycardia elicited by $10 \mu \mathrm{M}$ nicotine, in both, healthy and chagasic hearts.

Figure 5A shows that on healthy hearts $\alpha$-BGT (full circles) induced a significant bradycardia (-6.8 $\pm 3.1 \%$; $\mathrm{p}<0.05)$; however, in the presence of $10 \mu \mathrm{M}$ nicotine (open squares) $\alpha$-BGT blocked the nicotine-induced tachycardia. Figure 5B shows that the $\alpha$-BGT, by itself, had no effect on chagasic hearts' heart rate (full circles), but effectively blocked the nicotine-induced tachycardia (open squares).

In healthy hearts $10 \mathrm{nM} \mathrm{DH} \beta \mathrm{E}$, by itself, failed to induce a significant tachycardia ( $\mathrm{p}>0.05)$; however, in the presence of nicotine $(10 \mu \mathrm{M}), \mathrm{DH} \beta \mathrm{E}$ induced a significant $(\mathrm{p}<0.05)$ bradycardia (Figure $5 \mathrm{C})$. The chagasic hearts 

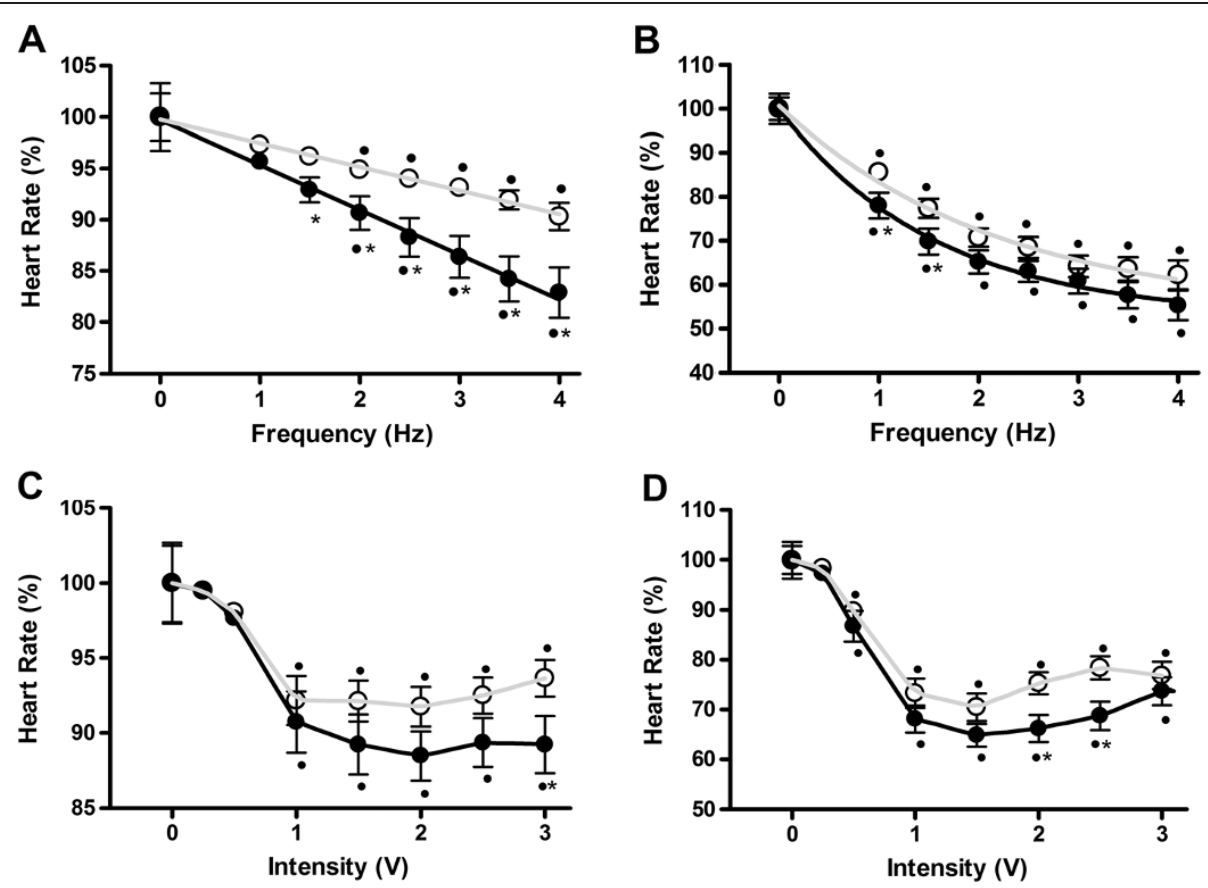

Figure 3 Vagal nerve stimulation in whole-animals. A 2 ms electric stimulation was delivered to the vagal nerve - at increasing frequency but fixed voltage (2 V) or increasing voltage at a fixed frequency $(1.5 \mathrm{~Hz})$ - in the absence $(\mathbf{A}$ and $\mathbf{C})$ or presence of $0.3 \mathrm{mg} / \mathrm{Kg}$ physostigmine (B and $\mathbf{D}$ ). In absence of physostigmine chagasic rats (open circles) the heart rate decreased proportionally to stimulus frequency (panel $\mathbf{A}$ ) or intensity (panel C). Physostigmine increased the vagal response in both groups; however, when higher stimulation frequencies were applied (i.e., $\geq 3 \mathrm{~Hz}$ ), the vagal response of chagasic animals became similar as compared with healthy rats. $p<0.05$ indicated statistical significant differences between groups $\left({ }^{*}\right)$ or to the basal rate $\left(^{(}\right)$.

response to DHßE stimulation alone was a delayed bradycardia (i.e., $10 \mathrm{~min}$ after stimulation). In the presence of nicotine, the delayed was abrogated (Figure 5D) and the response was comparable to that observed in the healthy hearts group.

\section{$P Q$ and $P R$ intervals}

Chagasic hearts had significantly prolonged PQ and PR intervals when compared to healthy hearts (healthy Rats:
$\mathrm{PQ}=46.82 \pm 2.49$ and PR: $53.70 \pm 2.37 \mathrm{~ms}$; chagasic rats: $\mathrm{PQ}=54.17 \pm 2.55$ and $\mathrm{PR}=61.92 \pm 2.48 \mathrm{~ms} ; \mathrm{p}=0.049$ and 0.041, respectively). The PQ interval in healthy hearts was significantly decreased by nicotine $10 \mu \mathrm{M}$, during the desensitized period (5 $\mathrm{min}$ ), an effect that was antagonized by MA, DH $\beta E$ and $\alpha-B G T$. No significant effect in chagasic hearts in the PQ interval was observed. Similar effects were observed for the PR intervals. When healthy and chagasic hearts were compared in a particular protocol
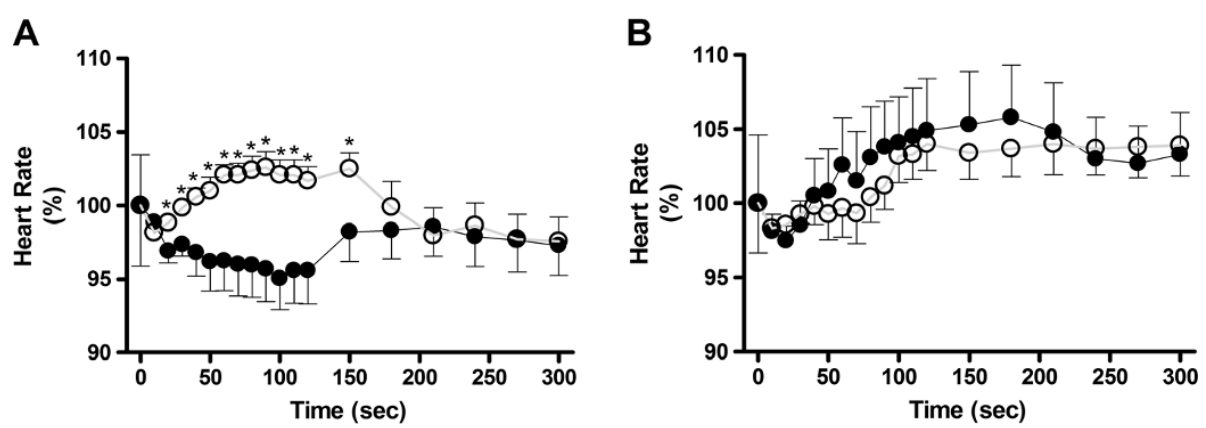

Figure 4 Nicotine induces a biphasic response in isolated beating-heart preparations. Nicotine at concentrations of $1 \mu \mathrm{M}$ (left panel) and $10 \mu \mathrm{M}$ (right panel) was perfused during $5 \mathrm{~min}$. The bipolar $400 \mathrm{~Hz}$ acquisition rate EKG records indicated that $1 \mu \mathrm{M}$ nicotine increased the heart rate of chagasic hearts (open circles), while decreasing it in healthy hearts (filled circles). $10 \mu \mathrm{M}$ nicotine induced a biphasic effect (i.e., transiently bradychardia followed by sustained tachycardia) on both healthy and chagasic animals' heart rate. ${ }^{*} \mathrm{p}<0.05$ indicated statistically significant difference compared to pre-drug basal rate. 

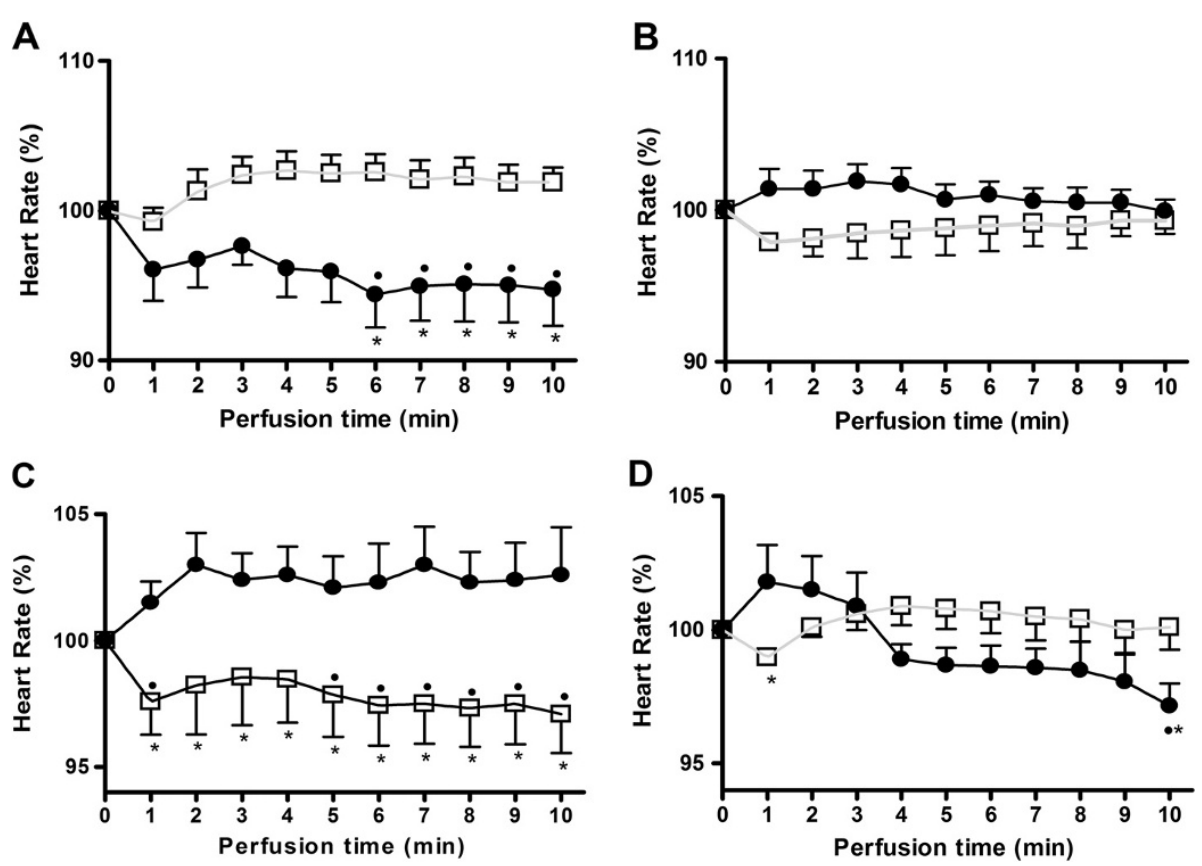

Figure $5 \mathrm{a}-\mathrm{BGT}$ and $\mathrm{DH} \beta E$ pharmacological effects on isolated beating-heart preparations. The nicotinic antagonists $\alpha-B G T$ (panels $\mathbf{A}$ and $\mathbf{B}$ ) and $\mathrm{DH} \beta E$ (panels $\mathbf{C}$ and $\mathbf{D}$ ) were perfused in the absence (black circles) or presence (open squares) of $10 \mu \mathrm{M}$ nicotine in healthy (panels $\mathbf{A}$ and $\mathbf{C}$ ) and chagasic (panel $\mathbf{B}$ and $\mathbf{D}$ ) hearts. Observe that $\alpha-B G T$ or DHßE, in healthy hearts, induced a significant bradycardia that counteracted the nicotine effect. $p<0.05$ indicates statistically significant difference between drug's group $\left(^{*}\right)$ or to the basal heart rate $(\bullet)$.

variable, we observed significant differences with $10 \mu \mathrm{M}$ nicotine during the desensitizing period, $100 \mu \mathrm{M}$ nicotine during the activation period, DH $\beta E$ and $\alpha B G T$ (Table 1).

\section{QT and QTc intervals}

No significant effects on either of the intervals were observed when healthy and chagasic hearts were compared. Furthermore, we did not observe any significant effect of nicotine on both intervals; however, in chagasic hearts with the addition of $10 \mu \mathrm{M}$ nicotine (activation period), DHßE and $\alpha$-BGT significantly increased the QTc interval when compared to nicotine only. When healthy and chagasic hearts were compared in a particular protocol variable we observed significant differences with $10 \mu \mathrm{M}$ nicotine during the desensitizing period and $\mathrm{DH} \beta \mathrm{E}$.

\section{$T$ and QRS amplitude}

QRS amplitude was higher in healthy hearts when compared with chagasic hearts (HR: $709 \pm 103.8 \mu \mathrm{V}$; CH: 462.1 $\pm 62.53 \mu \mathrm{V} ; \mathrm{p}=0.05)$. In healthy hearts, $10 \mu \mathrm{M}$ nicotine in the presence of MA and DH $\beta E$ only, induced a significantly decrease of the QRS amplitude; while in chagasic hearts $1 \mu \mathrm{M}$ nicotine and $10 \mu \mathrm{M}$ nicotine in the presence of DH $\beta E$ induced a significant decrease of QRS amplitude. When healthy and chagasic hearts were compared in a particular protocol variable we observed significant differences with $100 \mu \mathrm{M}$ nicotine during the desensitizing period and DH $\beta E$.

No differences for the $\mathrm{T}$ wave amplitude were observed between healthy and chagasic hearts. In healthy and chagasic hearts nicotine $10 \mu \mathrm{M}$ in addition to $\mathrm{DH} \beta \mathrm{E}$ induced a significant decrease of the T amplitude during the desensitizing period. When healthy and chagasic hearts were compared in a particular protocol variable we observed significant differences with $10 \mu \mathrm{M}$ nicotine in addition to MA during the desensitizing period.

\section{Perfusion pressure}

In healthy and chagasic hearts $10 \mu \mathrm{M}$ nicotine induced a significant increases of the pressure wave amplitude during the activation period, an effect that was blocked by MA and $\mathrm{DH} \beta \mathrm{E}$ in healthy hearts and by MA, DH $\beta \mathrm{E}$ and $\alpha \mathrm{BGT}$ in chagasic hearts. The use of $100 \mu \mathrm{M}$ nicotine also induced an increase of the pressure wave amplitude during the activation period in healthy hearts but not in chagasic ones. When healthy and chagasic hearts were compared in a particular protocol variable we observed significant differences with $10 \mu \mathrm{M}$ nicotine in addition to $\alpha B G T$ during activation and desensitizing periods (Table 1).

\section{Discussion}

This work represents the first study that evaluates the functional integrity of the nicotinic cholinergic system in 
Table 1 Effect of nicotine and a selective nicotinic antagonist on electrocardiographic parameters in isolated beating heart

\begin{tabular}{|c|c|c|c|c|c|c|c|c|}
\hline \multirow[t]{3}{*}{ Protocol Sequence } & \multicolumn{4}{|c|}{$P Q$ interval } & \multicolumn{4}{|c|}{ Aorta Pressure Wave } \\
\hline & \multicolumn{2}{|c|}{ Healthy Hearts } & \multicolumn{2}{|c|}{ Chagasic Hearts } & \multicolumn{2}{|c|}{ Healthy Hearts } & \multicolumn{2}{|c|}{ Chagasic Hearts } \\
\hline & $\mathrm{AV}$ (msec) & $\%$ & $\mathrm{AV}$ (msec) & $\%$ & $\mathrm{AV}(\mathrm{mmHg})$ & $\%$ & $\mathrm{AV}(\mathrm{mmHg})$ & $\%$ \\
\hline Basal & $46.8 \pm 2.5$ & 100 & $54.2 \pm 2.6^{@}$ & 100 & $14.1 \pm 2.3$ & 100 & $14.4 \pm 1.4$ & 100 \\
\hline Nic $1 \mu \mathrm{M} \mathrm{A}$ & $44.9 \pm 1.7$ & $97.2 \pm 3.0$ & $53.0 \pm 2.5$ & $96.2 \pm 0.3$ & $15.8 \pm 2.6$ & $141.0 \pm 29.72$ & $15.6 \pm 2.2$ & $110.7 \pm 11.2$ \\
\hline Nic $1 \mu \mathrm{M} \mathrm{D}$ & $47.1 \pm 2.4$ & $101.7 \pm 4.3$ & $53.3 \pm 3.0$ & $95.7 \pm 1.3$ & $13.6 \pm 1.9$ & $124.7 \pm 28.72$ & $13.3 \pm 1.5$ & $96.0 \pm 10.0$ \\
\hline Wash 1 & $49.9 \pm 1.9$ & 100 & $53.7 \pm 2.2$ & 100 & $11.6 \pm 1.6$ & 100 & $12.9 \pm 1.5$ & 100 \\
\hline Nic $10 \mu \mathrm{M} \mathrm{A}$ & $48.9 \pm 2.0$ & $98.1 \pm 2.2$ & $53.8 \pm 2.3$ & $100.3 \pm 1.7$ & $16.7 \pm 1.9^{*}$ & $180.9 \pm 37.74$ & $16.9 \pm 1.9^{*}$ & $134.8 \pm 9.8$ \\
\hline Nic $10 \mu \mathrm{M} D$ & $45.4 \pm 2.2^{*}$ & $90.7 \pm 2.2$ & $54.2 \pm 2.5$ & $104.6 \pm 2.0^{@}$ & $14.6 \pm 1.6$ & $159.5 \pm 31.96$ & $13.6 \pm 1.3$ & $112.8 \pm 8.7$ \\
\hline Wash 2 & $47.9 \pm 1.9$ & 100 & $55.8 \pm 2.6$ & 100 & $11.8 \pm 1.2$ & 100 & $12.6 \pm 1.5$ & 100 \\
\hline Nic $100 \mu \mathrm{M} A$ & $48.3 \pm 2.0$ & $101.0 \pm 2.4$ & $57.1 \pm 2.5$ & $109.0 \pm 1.5^{@}$ & $16.5 \pm 1.7^{*}$ & $150.4 \pm 17.21$ & $14.5 \pm 1.5$ & $120.1 \pm 9.7$ \\
\hline Nic $100 \mu \mathrm{M} D$ & $48.7 \pm 2.0$ & $101.4 \pm 2.9$ & $54.5 \pm 2.6$ & $100.5 \pm 1.2$ & $12.8 \pm 1.6$ & $107.1 \pm 5.75$ & $13.4 \pm 1.5$ & $112.7 \pm 12.6$ \\
\hline Wash 3 & $48.1 \pm 2.1$ & 100 & $51.2 \pm 2.6$ & 100 & $12.9 \pm 1.4$ & 100 & $13.1 \pm 1.2$ & 100 \\
\hline MA & $47.4 \pm 2.0$ & $99.6 \pm 3.8$ & $53.0 \pm 2.4$ & $103.4 \pm 1.7$ & $11.7 \pm 1.5$ & $90.5 \pm 8.13$ & $12.3 \pm 1.3$ & $95.3 \pm 6.4$ \\
\hline $\mathrm{MA}+\mathrm{Nic} 10 \mu \mathrm{M} A$ & $48.2 \pm 2.3$ & $100.3 \pm 2.1$ & $52.7 \pm 2.05$ & $104.3 \pm 1.1$ & $12.5 \pm 2.3$ & $92.7 \pm 9.64$ & $11.4 \pm 1.3$ & $88.7 \pm 6.0^{\circ}$ \\
\hline $\mathrm{MA}+$ Nic $10 \mu \mathrm{M} \mathrm{D}$ & $48.6 \pm 2.9$ & $101.2 \pm 2.8^{\circ}$ & $53.6 \pm 2.4$ & $102.8 \pm 0.4$ & $12.4 \pm 1.6$ & $94.4 \pm 7.88$ & $11.4 \pm 1.4$ & $87.7 \pm 6.6^{\circ}$ \\
\hline Wash 4 & $46.6 \pm 2.4$ & 100 & $53.9 \pm 2.1$ & 100 & $10.3 \pm 1.5$ & 100 & $11.5 \pm 1.3$ & 100 \\
\hline $\mathrm{DH} \beta \mathrm{E}$ & $47.4 \pm 2.4$ & $101.7 \pm 1.7$ & $55.4 \pm 2.5$ & $107.8 \pm 0.5^{@}$ & $12.4 \pm 2.1$ & $121.9 \pm 15.10$ & $10.7 \pm 1.2$ & $95.4 \pm 3.7$ \\
\hline $\mathrm{DH} \beta \mathrm{E}+\mathrm{Nic} 10 \mu \mathrm{M} \mathrm{A}$ & $49.0 \pm 2.6$ & $105.5 \pm 1.8^{\circ}$ & $55.8 \pm 2.5$ & $104.7 \pm 0.6$ & $11.2 \pm 1.8$ & $110.0 \pm 12.80^{\circ}$ & $11.0 \pm 1.2$ & $98.5 \pm 4.5^{\circ}$ \\
\hline $\mathrm{DH} \beta \mathrm{E}+\mathrm{Nic} 10 \mu \mathrm{M} \mathrm{D}$ & $48.8 \pm 1.9$ & $105.6 \pm 2.2^{\circ}$ & $55.6 \pm 2.3$ & $106.8 \pm 0.7$ & $10.4 \pm 1.7$ & $99.8 \pm 8.64^{\circ}$ & $10.8 \pm 1.2$ & $96.3 \pm 4.4$ \\
\hline Wash 5 & $48.4 \pm 2.1$ & 100 & $55.8 \pm 2.6$ & 100 & $10.0 \pm 1.9$ & 100 & $10.1 \pm 0.9$ & 100 \\
\hline aBGT & $50.6 \pm 2.1$ & $104.9 \pm 2.9$ & $55.3 \pm 2.5$ & $97.2 \pm 0.9^{@}$ & $7.7 \pm 1.4$ & $84.3 \pm 7.33$ & $10.6 \pm 1.0$ & $104.2 \pm 3.8$ \\
\hline aBGT+Nic $10 \mu \mathrm{M} \mathrm{A}$ & $50.3 \pm 1.9$ & $104.4 \pm 1.9^{\circ}$ & $56.0 \pm 2.9$ & $81.3 \pm 3.6$ & $9.4 \pm 1.7^{*}$ & $96.5 \pm 5.52^{\circ}$ & $8.9 \pm 1.2$ & $99.0 \pm 5.2^{\circ @}$ \\
\hline aBGT+Nic $10 \mu \mathrm{M} \mathrm{D}$ & $49.4 \pm 1.8$ & $102.6 \pm 2.4$ & $57.4 \pm 2.6$ & $106.6 \pm 1.7$ & $10.3 \pm 2.1$ & $105.2 \pm 12.35$ & $9.7 \pm 1.2$ & $95.4 \pm 3.8^{@}$ \\
\hline Wash 6 & $50.3 \pm 2.1$ & - & $57.8 \pm 2.7$ & - & $10.4 \pm 1.0$ & - & $9.3 \pm 1.7$ & - \\
\hline
\end{tabular}

A: agonist activation period at $30 \mathrm{sec}$ of perfusion; D: agonist desensitization period at 5 min of perfusion; AV: absolute values; Nic: nicotine; MA: mecamylamine; $\mathrm{DH} \beta \mathrm{E}$ : dihydro-beta-erythroidine; aBGT: alfa-bungarotoxin; * means $\mathrm{p}<0.05$ when absolute values are compared against basal or wash periods by repeated measure ANOVA followed by Dunnet post-test; ${ }^{\circ}$ means $p<0.05$ when $\%$ values are compared in the presence and absence of the antagonist by Wilconxon matched pairs test; ${ }^{@}$ means $\mathrm{p}<0.05$ when \% values are compared between healthy and chagasic groups by Mann-Whitney test.

rats with chronic chagasic disease, using electrophysiological tools. We were able to determine that rats with Chagas disease have a dysfunction of nicotinic cholinergic system when compared with healthy rats.

In our whole-animal model, nicotine induced bradycardia, an effect that could be mediated by the simultaneous activation of the post-synaptic autonomic neurons and inhibition of adrenergic pre-synaptic terminals innervating the heart. The inhibition of the adrenergic response most likely is mediated by M2 muscarinic AChRs. M2-mediated inhibitory effect has been demonstrated in guinea pig, where muscarinic agonists reduced norepinephrine overflow, in a concentration-dependent manner, and such effect was selectively antagonized by the M2-specific antagonist AF-DX-116 [16].

The tachycardia induced by nicotine, in the presence of isoproterenol, indicates an impairment in the vasovagal reflex in chagasic rats. Isoproterenol increases the systolic pressure, due to the increment on heart rate and ejection fraction. The damaged cholinergic parasympathetic efferents favored a post-synaptic $\beta$-adrenergic dominance over the heart rate. This observation was consistent with reports that, in rats, phenylephrine-induced bradycardia was diminished in the indeterminate phase of Chagas disease as well as in chronic chagasic cardiomyopathy [14].

Direct stimulation of the vagus nerve, in rats with chronic Chagas disease, decreased the bradycardic response as a function of stimuli frequency and intensity, indicating a reduced vagal function in chagasic rats. The importance of the vagus nerve's functional integrity has been documented in rats with acute chagasic myocarditis using direct vagal stimulation [17]. In these studies, the chronotropic response to stimulation, with low frequencies pulses, was significantly different between chagasic rats and healthy rats. These groups have comparable chronotropic response to higher frequency stimuli suggesting decrease in the fibers' excitability and change in their response threshold in chagasic rats, due to acute nerve inflammation.

In Chagas disease, the diminished cholinergic function has been explained as a direct consequence of the presence of autoantibodies against both types of AChRs (i.e., nicotinic and muscarinic receptors). The chronic 
binding of these autoantibodies to the nAChR could induce a decrease in the population of functional nAChRs and consequently contribute to the alterations described in the course of chronic Chagas' disease [6,7]. In our experiments, we observed that when physostigmine, a well known acetyl cholinesterase inhibitor, was administered at the same time of high frequencies stimuli, the vagal response was restored. By mass-action law, a high level of synaptic acetylcholine would competitively displace the autoantibodies from the receptor sites.

In our isolated beating-heart model, nicotine stimulation induced the classic biphasic heart rate, which has been described for both nicotine and other non-selective AChR agonists [18-21]. However, our study demonstrated the nicotine-induced effect was dose-dependent. While $1 \mu \mathrm{M}$ nicotine induced a bradycardia only, $100 \mu \mathrm{M}$ of nicotine induced a biphasic effect in control rats. These differential responses were blocked by $1 \mu \mathrm{M}$ mecamylamine, indicating that the action of nicotine used the ganglionic $\alpha 3 \beta 4$ nicotine acetylcholine receptor (nAChR) signaling.

The need of an intact ganglionic transmission has been demonstrated on elegant studies using hexamethonium. This ganglionic $\mathrm{nAChR}$ antagonist blocked the nicotineinduced biphasic heart rate [10,19-21]. However, the exact $\mathrm{nAChR}$ population involved in the nicotine-induced bradycardia has not been identified. Successful blockade of nicotine-induced bradycardia by $\alpha$-BGT suggest that $\alpha 7$ nAChR subtype could be involved in the biphasic heartrate response to nicotine stimulation [19]. Involvement of other nAChR subtypes or even the contribution of specific subunits cannot be ignored. nAChR with high affinity for nicotine are preferentially formed by $\alpha 2, \alpha 4$ and $\beta 2$ subunits [22-24]. $\alpha 2 \beta 2$ and $\alpha 4 \beta 2$ receptors have been described to be expressed on intracardiac neurons [9]. DH $\beta E$, an $\alpha 4 \beta 2$ nAChR selective antagonist, prevented nicotineinduced bradycardia, while a selective agonist (RJR2403) reproduced the nicotine effect $[20,21]$. Cytisine, a selective $\beta 4$ subunit agonist, and metillycaconitine (selective $\alpha 7$ antagonist) have opposites effect on the heart rate [19-21].

Our results indicated that pre-synaptic $\alpha 7 \mathrm{nAChRs}$ are involved in the nicotine-induced tachycardic phase as it was blocked by $\alpha-B G T$. The bradycardic response to $\alpha$-BGT perfused alone suggested that $\alpha 7$ subunit is also present in nAChR intrinsic adrenergic neurons. Recent studies have found that autonomic dysfunction; especially a decrease of vagal activity, is related to worsening of cardiovascular diseases. Autonomic imbalance with increased adrenergic and reduced parasympathetic activity is involved in the development and progress of heart failure (HF) [25]. M2-AChR knockout mice exhibit impaired ventricular function and increased susceptibility to cardiac stress, suggesting a protective role of the parasympathetic nervous system in the heart [26]. Furthermore, vagal stimulation has been shown to be beneficial in cases of heart failure, because it inhibited cardiac remodeling associated with heart dysfunction $[27,28]$.

Our results suggest that nicotinic receptors are involved in the regulation of electrical transmission between sinusal and AV nodes, however chagasic hearts have lost this capability because nicotine was unable to shorten PQ and PR intervals in them, indicating a disregulation of nicotinic receptors in these structures. Indeed a lost of nicotinic receptors could explain a prolongued $\mathrm{PQ}$ and $\mathrm{PR}$ intervals observed in chagasic hearts in basal conditions.

The increase of perfusion pressure wave induced by nicotine in both groups reflects a positive inotropic effect of the agonist acting on nicotinic receptors. It has been already reported that nicotine produced a concentrationdependent positive inotropic effect on electrical evoked contraction of isolated toad ventricle [29].

\section{Conclusions}

Our results support the hypothesis that cholinergic dysfunction in Chagas disease is the result of a combined disruption of the vagal transmission and trophic remodeling of intracardiac neurons and receptors. The importance of our findings is to demonstrated that alterations in cardiac nicotinic cholinergic transmission is present in Chagas disease in an early phase of cardiomyopathy evolution, before a dilated cardiomyopathy with congestive heart failure will be installed. Therefore cardiac nicotinic cholinergic functionality could be useful as prognostic marker of the disease.

\section{Competing interest}

The authors declare that they have not competing interests.

\section{Authors' contribution}

RBC and CRB: made substantial contributions to conception and design, carried out whole-animal studies including data acquisition, analysis and interpretation, and wrote the draft and final version of the manuscript. ELH, RFZ and LFM: contributed to conception, design and performance of isolated beating-heart studies including data acquisition and analysis, involved in drafting the manuscript. MDM and EJM: contributed to conception, design and performance of vagal nerve stimulation studies, including data acquisition and analysis and were involved in drafting the manuscript. All authors read and approved the final version of the manuscript.

\section{Acknowledgements}

This study was funded by the "Consejo de Desarrollo Científico, Humanístico y Tecnológico" (CDCHT) grants Nº02-ME-2004 and 006-ME-2008, Universidad Centro Occidental "Lisandro Alvarado", Barquisimeto, Lara, Venezuela. The authors would like to thank Dr. Carla R. Lankford (US FDA, Silver Spring, Maryland, USA) for poof-reading this manuscript.

\section{Author details}

${ }^{1}$ Biochemistry Research Units, Health Sciences School, Universidad Centro Occidental Lisandro Alvarado, Barquisimeto, Lara, Venezuela. ${ }^{2}$ Medical Parasitology Research Units, Health Sciences School, Universidad Centro Occidental Lisandro Alvarado, Barquisimeto, Lara, Venezuela. ${ }^{3}$ Libertador Av. con Andrés Bello, Unidad de Bioquímica, Decanato de Ciencias de la Salud, Universidad Centro-Occidental "Lisandro Alvarado", Barquisimeto, Estado Lara Código Postal: 3001, Venezuela. 
Received: 11 April 2012 Accepted: 21 December 2012

Published: 7 January 2013

\section{References}

1. Rassi A Jr, Rassi A, Marin-Neto JA: Chagas disease. Lancet 2010, 375(9723):1388-1402.

2. Aché A, Matos AJ: Interrupting Chagas disease transmission in Venezuela. Rev Inst Med Trop Sao Paulo 2001, 43:37-43.

3. Dávila DF, Santiago JJ, Odreman WA: Vagal dysfunction and the pathogenesis of chronic Chagas disease. Int J Cardiol 2005, 100:337-339.

4. Kierszenbaum F: Where do we stand on the autoimmunity hypothesis of Chagas disease? Trends Parasitol 2005, 21:513-516.

5. Sterin-Borda L, Borda E: Role of neurotransmitter autoantibodies in the pathogenesis of chagasic peripheral dysautonomia. Ann N Y Acad Sci 2000, 917:273-280

6. Goin JC, Venera G, Biscoglio de Jimenez Bonino M, Sterin-Borda L: Circulating antibodies against nicotinic acetylcholine receptors in chagasic patients. Clin Exp Immunol 1997, 110:219-225.

7. Hernández CC, Barcellos LC, Giménez LE, Cabarcas RA, Garcia S, Pedrosa RC, Nascimento JH, Kurtenbach E, Masuda MO, Campos de Carvalho AC: Human chagasic IgGs bind to cardiac muscarinic receptors and impair L-type Ca2+ currents. Cardiovasc Res 2003, 58:55-65.

8. Fischer H, Liu DM, Lee A, Harries JC, Adams DJ: Selective modulation of neuronal nicotinic acetylcholine receptor channel subunits by Go-protein subunits. J Neurosci 2005, 25:3571-3577.

9. Poth K, Nutter T, Cuevas J, Parker M, Adams D, y Luetje C: Heterogeneity of nicotinic receptor class and subunit mRNA expression among individual parasympathetic neurons from rat intracardiac ganglia. J Neurosci 1997, 2:586-596.

10. Bibevski S, Zhou Y, Mclntosh M, Zigmond R, y Dunlap M: Functional nicotinic acetylcholine receptors that mediate ganglionic transmission in cardiac parasympathetic neurons. J Neurosci 2000, 13:5076-5082.

11. Cuevas J, Berg D: Mammalian nicotinic receptor with alpha 7 subunits that slowly desensitize and rapidly recover from alpha-bungarotoxin blockade. J Neurosci 1998, 18:10335-10344.

12. Purnyn HE, Rikhalsky OV, Skok MV, Skok VI: Functional nicotinic acetylcholine receptors in the neurons of rat intracardiac ganglia. Fiziol Zh 2004, 50:79-84.

13. Peraza-Cruces K, Gutiérrez-Guédez L, Castañeda Perozo D, Lankford CR, Rodríguez-Bonfante C, Bonfante-Cabarcas R: Trypanosoma cruzi infection induces up-regulation of cardiac muscarinic acetylcholine receptors in vivo and in vitro. Braz J Med Biol Res 2008, 41:796-803.

14. Labrador-Hernández M, Suárez-Graterol O, Romero-Contreras $U$, Rumenoff $L$, Rodríguez-Bonfante C, Bonfante-Cabarcas R: The cholinergic system in cyclophosphamide-induced Chagas dilated myocardiopathy in Trypanosoma-cruzi-infected rats: an electrocardiographic study. Invest Clin 2008, 49:207-224.

15. Alkondon M, Albuquerque EX: Diversity of nicotinic acetylcholine receptors in rat hippocampal neurons. I. Pharmacological and functional evidence for distinct structural subtypes. J Pharmacol Exp Ther 1993, 265:1455-1473.

16. Haunstetter A, Haass M, Yi X, Krüger C, Kübler W: Muscarinic inhibition of cardiac norepinephrine and neuropeptide $Y$ release during ischemia and reperfusion. Am J Physiol 1994, 267:R1552-R1558.

17. Dávila DF, Gottberg CF, Donis JH, Torres A, Fuenmayor AJ, Rossell O: Vagal stimulation and heart rate slowing in acute experimental chagasic myocarditis. J Auton Nerv Syst 1988, 25:233-234.

18. Cardinal R, Pagé P: Neuronal modulation of atrial and ventricular electrical properties. In Basic and Clinical Neurocardiology. Edited by Armour JA, Ardell JL. NY: Oxford University Press; 2004:315-399.

19. Ji S, Tosaka T, Whitfield BH, Katchman AN, Kandil A, Knollmann BC, Ebert SN: Differential rate responses to nicotine in rat heart: evidence for two classes of nicotinic receptors. J Pharmacol Exp Ther 2002, 301:893-899.

20. Li YF, Lacroix C, Freeling J: Cytisine induces autonomic cardiovascular responses via activations of different nicotinic receptors. Auton Neurosci 2010, 154:14-19.

21. Li YF, LaCroix C, Freeling J: Specific subtypes of nicotinic cholinergic receptors involved in sympathetic and parasympathetic cardiovascular responses. Neurosci Lett 2009, 462:20-23.

22. Chavez-Noriega LE, Crona JH, Washburn MS, Urrutia A, Elliott KJ, Johnson EC: Pharmacological characterization of recombinant human neuronal nicotinic acetylcholine receptors $\mathrm{h}$ alpha 2 beta $2, \mathrm{~h}$ alpha 2 beta $4, \mathrm{~h}$ alpha 3 beta 2, h alpha 3 beta 4, h alpha 4 beta 2, h alpha 4 beta 4 and h alpha 7 expressed in Xenopus oocytes. J Pharmacol Exp Ther 1997, 280:346-356.

23. Xiao Y, Kellar KJ: The comparative pharmacology and up-regulation of rat neuronal nicotinic receptor subtype binding sites stably expressed in transfected mammalian cells. J Pharmacol Exp Ther 2004, 310:98-107.

24. Parker MJ, Beck A, Luetje CW: Neuronal nicotinic receptor beta2 and beta4 subunits confer large differences in agonist binding affinity. Mol Pharmacol 1998, 54:1132-1139.

25. Klein HU, Ferrari GM: Vagus nerve stimulation: A new approach to reduce heart failure. Cardiol J 2010, 17:638-644.

26. LaCroix C, Freeling J, Giles A, Wess J, Li YF: Deficiency of M2 muscarinic acetylcholine receptors increases susceptibility of ventricular function to chronic adrenergic stress. Am J Physiol Heart Circ Physiol 2008, 294:H810-H820

27. Castro RR, Porphirio G, Serra SM, Nóbrega AC: Cholinergic stimulation with pyridostigmine protects against exercise induced myocardial ischaemia. Heart 2004, 90:1119-1123.

28. Lara A, Damasceno DD, Pires R, Gros R, Gomes ER, Gavioli M, Lima RF, Guimarães D, Lima P, Bueno CR Jr, Vasconcelos A, Roman-Campos D, Menezes CA, Sirvente RA, Salemi VM, Mady C, Caron MG, Ferreira AJ, Brum PC, Resende RR, Cruz JS, Gomez MV, Prado VF, de Almeida AP, Prado MA, Guatimosim S: Dysautonomia due to reduced cholinergic neurotransmission causes cardiac remodeling and heart failure. Mol Cell Biol 2010, 30:1746-1756.

29. Koley J, Saha JK, Koley BN: Positive inotropic effect of nicotine on electrically evoked contraction of isolated toad ventricle. Arch Int Pharmacodyn Ther 1984, 267:269-278.

doi:10.1186/2050-6511-14-2

Cite this article as: Bonfante-Cabarcas et al.: Electrophysiological and pharmacological evaluation of the nicotinic cholinergic system in chagasic rats. BMC Pharmacology and Toxicology 2013 14:2.

\section{Submit your next manuscript to BioMed Central and take full advantage of:}

- Convenient online submission

- Thorough peer review

- No space constraints or color figure charges

- Immediate publication on acceptance

- Inclusion in PubMed, CAS, Scopus and Google Scholar

- Research which is freely available for redistribution 